\title{
Moving Beyond Luminal Stenosis: Imaging Strategies for Stroke Prevention in Asymptomatic Carotid Stenosis
}

\author{
Ajay Gupta $^{a}$, b Randolph S. Marshall ${ }^{c}$ \\ ${ }^{a}$ Department of Radiology, ${ }^{b}$ Brain and Mind Research Institute, Weill Cornell Medical College, and ${ }^{\mathrm{C}}$ Department of \\ Neurology, Columbia University Medical Center, New York, N.Y., USA
}

\section{Key Words}

Carotid stenosis · MRI · Ultrasound · Transcranial Doppler · Stroke

\begin{abstract}
Background: With progressive improvements in medical therapy and resultant reductions in stroke risk, luminal stenosis criteria are no longer adequate to inform decisions to pursue surgical revascularization in patients with asymptomatic carotid artery stenosis. Summary: In this evidencebased review, we discuss the imaging-based risk stratification strategies that take into account factors beyond luminal stenosis measurements, including cerebral hemodynamics and plaque composition. The existing literature lends support to the use of certain imaging tests in patients with asymptomatic carotid stenosis including cerebrovascular reserve testing, MRI of plaque composition, ultrasound of plaque echolucency, and transcranial Doppler evaluation for microemboli. The highest quality evidence thus far in the literature includes only systematic reviews and meta-analyses of cohort studies with no randomized trials having yet been performed to show how these newer imaging biomarkers could be used to inform treatment decisions in asymptomatic carotid stenosis. Beyond the need for randomized trials, there are additional important steps needed to improve the relevance of evidence supporting risk assessment strategies.
\end{abstract}

Imaging studies evaluating the risk of stroke in carotid disease should clearly define asymptomatic versus symptomatic disease, use uniform definitions of clearly defined outcome measures such as ipsilateral stroke, ensure that imaging interpretations are performed in a manner blinded to treatments and other risk factors, and include cohorts which are on modern intensive medical therapy. Such studies of risk stratification for asymptomatic carotid stenosis will be most valuable if they can integrate multiple high-risk features (including clinical risk factors) into a multi-factorial risk assessment strategy in a manner that is relatively simple to implement and generalizable across a wide range of practice settings. Key Messages: Together, modern imaging strategies allow for a more mechanistic assessment of stroke risk in carotid disease compared to luminal stenosis measurements alone, which, with further validation in randomized controlled trials, may improve current efforts at stroke prevention in asymptomatic carotid stenosis.

(C) 2015 S. Karger AG, Basel

\section{Clinical Background}

Various angiographic measurements of vessel narrowing have long played a central role in stroke risk stratification in patients with carotid artery stenosis, the cause of approximately $10-15 \%$ of all ischemic strokes [1]. Lu-

\section{KARGER 125}

(c) 2015 S. Karger AG, Base

$1015-9770 / 15 / 0396-0253 \$ 39.50 / 0$

E-Mail karger@karger.com

www.karger.com/ced
Ajay Gupta, MD

Department of Radiology, Weill Cornell Medical College

525 East 68th Street, Starr 8A, Box 141

New York, NY 10065 (USA)

E-Mail ajg9004@med.cornell.edu 
minal stenosis measurements determined by catheter angiography were used to select patients for the first major treatment trials of carotid stenosis, including the North American Symptomatic Carotid Endarterectomy Trial [2] and the European Carotid Surgery Trial [3]. These trials, which began enrolling participants in the 1980s, showed that carotid endarterectomy reduced the risk of stroke in symptomatic subjects with high-grade carotid artery stenosis. Soon thereafter, randomized surgical versus medical treatment trials of asymptomatic carotid stenosis patients followed $[4,5]$, and though the magnitude of stroke risk reduction was less than in symptomatic patients, these studies also confirmed that carotid endarterectomy was beneficial in preventing stroke in asymptomatic patients selected based on stenosis severity.

In more recent years, however, improvements in medical therapy for stroke prevention have caused increasing controversy [6-10] about the role of surgical revascularization in the treatment of asymptomatic carotid stenosis. In the intervening 20 years since the first large treatment trials [2-5], intensive medical therapy has dramatically reduced the annual risk of stroke in asymptomatic carotid stenosis patients [11]. In a recent meta-analysis of clinical trials of asymptomatic carotid stenosis patients recruited between 2000 and 2010, Raman et al. [12] calculated an annual stroke rate of $1.13 \%$, compared to an annual stroke rate of between 2 and 3\% for studies completing recruitment before 2000. Closer inspection of these data suggest that if only the most recent studies are included, the annual stroke risk may be less than $1 \%$ per year. For this reason, the modest stroke reduction benefit seen for asymptomatic carotid stenosis in these treatment trials is of questionable current relevance $[9,12]$ for patients receiving modern intensive medical therapy.

\section{Moving Beyond Luminal Stenosis as a Risk Metric}

In the face of the advances in medical management, luminal stenosis measurements are no longer adequate to identify those asymptomatic carotid stenosis patients at greatest risk of stroke. Recent trends in stroke risk in this population are in large part the reason why in its most recent set of guidelines [13] issued in 2014, the United States Preventive Task Force made a recommendation against population-based screening efforts to detect asymptomatic carotid stenosis. In its decision, the United States Preventive Task Force cited that beyond luminal stenosis measurements and traditional stroke risk factors, 'there are no externally validated, reliable methods to determine who is at increased risk ... for stroke when carotid artery stenosis is present'. Advances in imaging in recent years, however, have allowed imaging technology to be at the forefront of a more detailed and mechanistic assessment of stroke risk in carotid disease. In particular, the two main pathophysiologic mechanisms underlying stroke risk in large vessel arterial disease - the propensity of unstable plaque to embolize $[14,15]$ and downstream hemodynamic compromise (low flow) from high-grade stenosis [15-17] - can both be studied with various imaging strategies with the potential to more accurately identify those carotid disease patients at the greatest stroke risk. In the subsequent sections, we will review the updated state of imaging-based risk stratification techniques. We will focus on an evidence-based approach [18], focused on those imaging strategies in which a systematic review of data of randomized controlled trials (level 1a evidence) or systematic reviews of cohort studies (level 2a) are available. As such, we will focus on studies of patients with asymptomatic carotid stenosis who had baseline imaging to measure a particular risk factor (with or without treatment randomization) and then were followed for stroke or TIA (table 1).

\section{Hemodynamic Stroke Risk Assessment Strategies}

\section{Cerebrovascular Reserve Testing}

Hypoperfusion from hemodynamically significant stenosis can result in a decrease in cerebral perfusion pressure. In such cases, autoregulation of the cerebral vasculature can respond with compensatory vasodilation of the cerebral arterioles to maintain normal cerebral blood flow [19]. If there are further decreases in cerebral perfusion pressure from progressive increases in proximal stenosis, maximally dilated arterioles may be unable to maintain CBF in a normal range and thereby result in increased ischemic stroke risk [16]. This hemodynamic parameter has been called cerebrovascular reserve, and there have been two main approaches to measure this risk factor on imaging studies. One approach involves obtaining direct brain CBF measurements using PET [20], nuclear medicine techniques [21,22], CT perfusion [23], or MR perfusion [24, 25] before and after a vasodilatory stimulus. The second approach involves measurement of flow velocities as a surrogate for CBF [26-28] (typically in the MCA via transcranial Doppler) distal to a lesion both before and after a vasodilatory stimulus. Various vasodilatory stimuli have been reported in the literature; 
Table 1. Summary of studies with evidence supporting brain hemodynamic or plaque imaging-based methods of stroke risk stratification

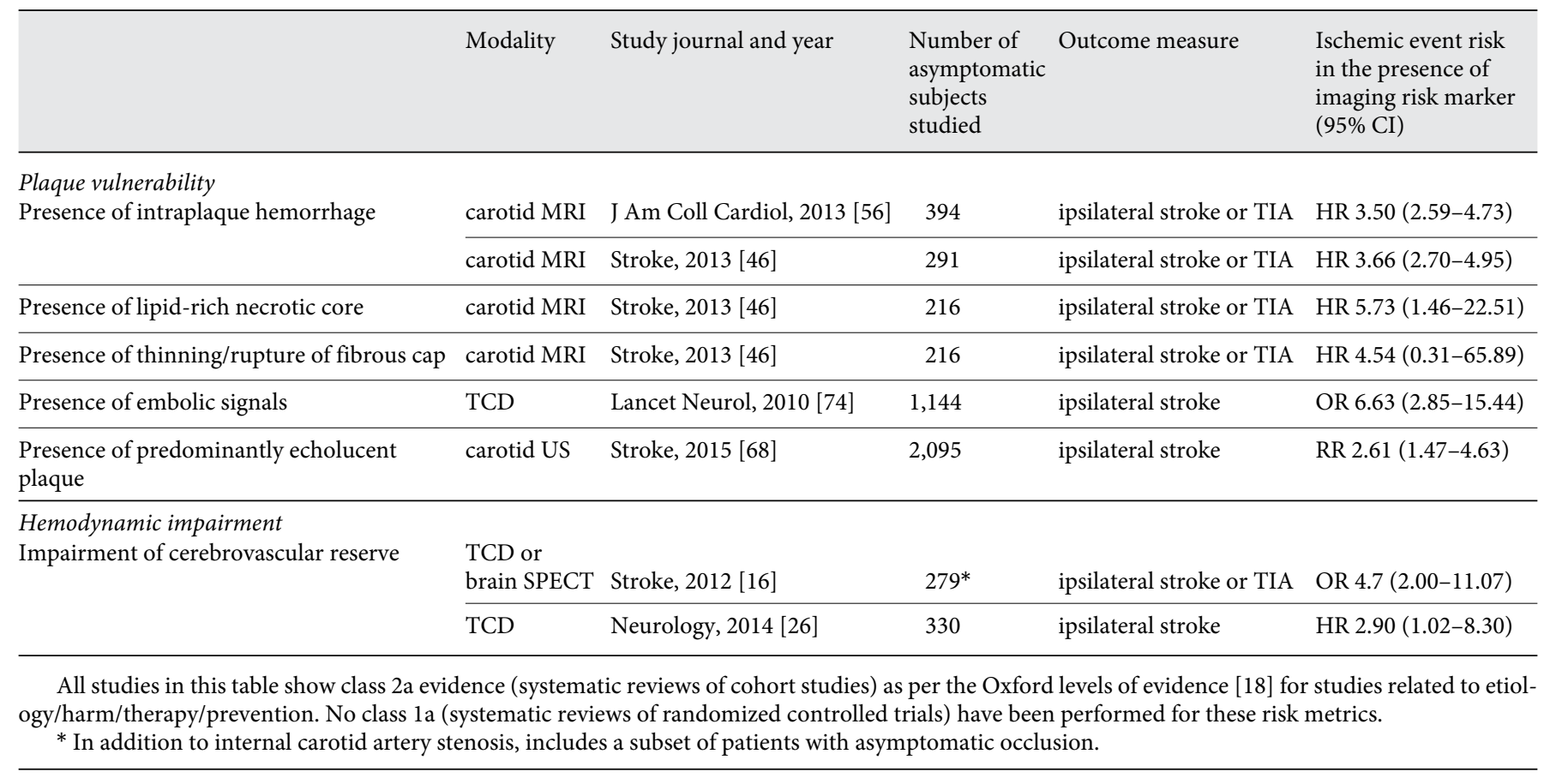

they include increasing levels of $\mathrm{CO}_{2}$ such as with breathholding or inhalation of gas mixtures [29] and pharmacological challenge with acetazolamide $[30,31]$.

A recent systematic review and meta-analysis [16] analyzed cerebrovascular reserve testing performed via transcranial Doppler or nuclear medicine flow studies in 13 published studies including nearly 1,000 patients with carotid stenosis or occlusion. With a mean follow-up of 3 years after baseline cerebrovascular reserve testing, the presence of impaired cerebrovascular reserve was associated with an approximately 4 -fold increased risk of future stroke compared with patients with similar stenosis severity or occlusion but with a normal cerebrovascular reserve. When analysis was limited to studies with asymptomatic carotid stenosis alone, a similar risk of future stroke was found, suggesting that cerebrovascular reserve impairment is a robust hemodynamic risk metric applicable to both symptomatic and asymptomatic carotid disease. More recently, a pooled meta-analysis [26] with individual patient data focused exclusively on transcranial Doppler cerebrovascular reactivity, and found that impaired cerebrovascular reserve was independently associated with increased risk of ipsilateral stroke in carotid disease (HR 3.69) including in a subset of patients only with asymptomatic stenosis (HR 2.90).

Moving Beyond Luminal Stenosis

\section{Oxygen Extraction Fraction Assessment}

Once cerebrovascular reserve is exhausted, a compensatory increase in brain tissue oxygen extraction fraction can occur to maintain aerobic metabolism in the brain $[19,32,33]$. Increase in oxygen extraction fraction as measured by ${ }^{15} \mathrm{O}$-PET is a well-studied hemodynamic stroke risk factor especially in symptomatic carotid occlusion [32, 34, 35]. A recent systematic review and meta-analysis of increased oxygen extraction fraction on ${ }^{15} \mathrm{O}-\mathrm{PET}$ in symptomatic carotid stenosis or occlusion showed that for a given degree of stenosis or occlusion of the internal carotid artery, increase in oxygen extraction is associated with a 6-fold increased stroke risk [36]. However, because of the logistical challenges associated with ${ }^{15} \mathrm{O}$-PET scanning (the need for a cyclotron and the 122 second half-life of the radiotracer ${ }^{15} \mathrm{O}$ ) very few reports exist on the role of oxygen extraction fraction measurement in asymptomatic carotid disease. According to the limited data published on asymptomatic carotid disease with ${ }^{15} \mathrm{O}$-PET, we estimate that there may be an approximately $10-20 \%$ prevalence of ${ }^{15} \mathrm{O}$ PET oxygen metabolism abnormalities in asymptomatic carotid stenosis patients, but there is some uncertainty about this prevalence given the limited data available for analysis. 


\section{Plaque Vulnerability for Stroke Risk Assessment}

\section{MRI Assessment of Carotid Plaque}

MRI, with its high spatial resolution and tissue discrimination capabilities, has been instrumental in elucidating the tissue types that are hallmarks of histopathologically defined high-risk plaque such as hemorrhage, lipid-rich necrotic core, and a thinned or ruptured fibrous cap [37]. Early fundamental investigations to characterize the in vivo tissue types composing carotid artery plaque were focused on the accurate characterization of vulnerable plaque elements via multi-sequence MRI with a dedicated surface carotid coil [38-40] using histologic analysis of plaque as a gold standard for comparison. Subsequent work [41-45] focused on whether MRI of carotid plaque composition could predict stroke or TIA. A recent systematic review and meta-analysis [46] on this topic showed that the MRI-defined presence of intraplaque hemorrhage, fibrous cap thinning or rupture, and lipid-rich necrotic core were all predictive of future ipsilateral stroke or TIA development, though the strength of the predictive ability remains somewhat uncertain for lipid-rich necrotic core and thinning/rupture given the relatively few prospective observational studies which have characterized these particular plaque elements. Indeed, of the vulnerable plaque composition elements detectable on MRI, intraplaque hemorrhage has been the most well studied [14, 42, 43, 47-55]. Unlike the detection of lipid-rich necrotic core and characterization of the fibrous cap that require a multi-sequence MRI protocol with a carotid coil, the presence of intraplaque hemorrhage can be detected with high diagnostic accuracy using a single sequence fat-suppressed T1-weighted sequence, which can be performed in less than 5 min [46]. An additional systematic review and meta-analysis [56] focused exclusively on the predictive ability of intraplaque hemorrhage found that the presence of MRI-detected intraplaque hemorrhage conferred a 3.5-fold risk of developing future stroke or TIA for a given degree of carotid stenosis. This analysis further concluded that the predictive value of plaque hemorrhage is not significantly different whether hemorrhage is detected using a multisequence acquisition with a carotid coil versus a single fat-suppressed T1-weighted sequence without a carotid coil.

\section{Ultrasound Assessment of Carotid Plaque and}

Mircoemboli

Though ultrasound lacks the specificity of plaque tissue characterization possible via MRI, it remains an at- tractive potential means of risk stratification as it is widely available, has almost no contraindications, and is less expensive than MRI. Though various sonographically determined plaque features have been proposed to aid in the identification of high-risk plaque such as plaque ulceration [57] or stenosis progression [58], perhaps the most well-studied [59-67] risk marker for which there is level $2 \mathrm{a}$ evidence [68] is the presence of predominantly echolucent plaque. Histopathologic investigations $[69,70]$ suggest that predominantly echolucent plaque may contain a relatively high proportion of lipid-rich necrotic core or intraplaque hemorrhage, which are the known constituents of more advanced, complicated atherosclerotic plaque $[37,38]$. There are two main methods of determining plaque echolucency: qualitative, subjective assessment of echolucency versus thresholded, quantitative gray-scale median value techniques. Though a few population-based studies had conflicting results about the predictive value of plaque echolucency, a recent meta-analysis [68] of over 7,000 patients from 7 studies concluded that predominantly echolucent carotid artery plaque predicted an increased relative risk of future stroke in patients with both nonstenosing and stenosing carotid plaque. In particular, in a subset analysis of patients with $50 \%$ or greater stenosis, the authors found that patients with predominantly echolucent plaque had an approximately 2.6-fold increased risk of ipsilateral stroke compared to subjects with predominantly echogenic plaque.

In addition to the direct anatomic characterization of carotid artery plaque, ultrasound techniques are also capable of detecting small, circulating emboli in the cerebral circulation via transcranial Doppler detection of embolic signals in the MCA ipsilateral to the stenotic ICA [71-74]. In this technique, which typically involves 30 to $60 \mathrm{~min}$ of recording of audible, high-intensity embolic signals, small microemboli can be detected with high diagnostic accuracy $[75,76]$. In the Asymptomatic Carotid Emboli Study, a prospective multi-center observational trial, the presence of embolic signals ipsilateral to a stenotic carotid artery conferred an approximately sixfold increased risk of future stroke compared to those subjects without embolic signals [74]. The Asymptomatic Carotid Emboli Study investigators also performed a meta-analysis using their own data plus other studies of asymptomatic carotid stenosis and found a similar predictive ability of positive embolic signals in predicting ipsilateral stroke (HR 6.63) in a pooled analysis of nearly 1,000 patients. 


\section{Future Directions in Stroke Risk Assessment Studies}

\section{Hemodynamic Risk Assessment Strategies}

Though nuclear medicine and transcranial Doppler methods have been used to measure cerebrovascular reserve in prospective cohort studies of stroke risk in carotid stenosis, to date, no such studies have occurred using modern CT or MRI perfusion techniques. Though CT perfusion and $\mathrm{T} 2 *$ dynamic susceptibility contrast MRI perfusion are well-established methods of studying CBF, because cerebrovascular reserve testing requires two separate measurements of $\mathrm{CBF}$ (both at rest and after a vasodilatory stimulus), the need to administer two separate contrast doses may limit the role of contrast-enhanced perfusion imaging for cerebrovascular reserve testing. Arterial spin labeling MRI and blood-oxygen-level dependent (BOLD) functional MRI (fMRI) are potentially more attractive blood flow measurement techniques that have been recently shown to be accurate and feasible methods of cerebrovascular reserve testing that can be repeated without the need for intravenous contrast administration [77-83]. Future prospective observational studies will be needed to determine whether these MRI perfusion techniques can play a role in the prediction of ipsilateral ischemic stroke in asymptomatic carotid stenosis. Similarly, recent investigations have shown that MRI-based techniques can quantify brain cerebral metabolic rate of oxygen and oxygen extraction fraction, which could replace invasive PET techniques by allowing noninvasive measurement of brain oxygen metabolism via standard MRI equipment. Recent studies with susceptibility weighted imaging techniques $[84,85]$ and fMRI BOLD $[78,86]$ for example, have shown the feasibility of novel methods of oxygen metabolism quantification with MRI, though future investigations with carotid stenosis subjects are still needed to assess the clinical utility of these approaches.

\section{Plaque Imaging Assessment Strategies}

With the exception of echolucency on ultrasound, most existing plaque-imaging techniques that we have described are relatively expensive and require access to MRI, thereby somewhat limiting simple and widespread implementation of these risk stratification strategies. Future work should emphasize those plaque-imaging strategies which can be generalized and used in a wide range of clinical settings. One such approach is the evaluation of carotid artery stenosis progression with serial sonography. Though to our knowledge there is no systematic review or meta-analysis on this topic, there are several studies [58,
87-90] suggesting that the progression of carotid stenosis detected by duplex sonography predicts adverse cardiovascular clinical events and ipsilateral stroke. The most recent of these studies by Hirt [58] analyzed about 1,500 carotid subjects from the Asymptomatic Carotid Stenosis Trial (ACST) and provides detailed stroke risk information based on stenosis progression over time in strictly defined NASCET stenosis subgroups (50-69\%, 70-89\%, $90-99 \%$, and $100 \%$ ). Clearly, though evaluation of highrisk plaque composition is highly valuable as it provides stroke risk information at a single time point, future stroke risk prediction studies would be strengthened by combining plaque vulnerability assessment with stenosis progression data, as most asymptomatic carotid stenosis patients do undergo periodic surveillance imaging.

Although rapidly evolving MRI technology has been improving the imaging of vulnerable carotid artery plaque, future investigations would also benefit from increased standardization of imaging sequences and interpretation parameters so that such technology could be more amenable to multicenter trials and would also be more generalizable in clinical practice [56]. Similarly, there is significant variability in the sonographic criteria used to define plaque echolucency, and therefore techniques that rely upon a quantitative imaging parameter, such as a normalized gray-scale median, may improve standardization of image assessment [63]. In addition, though to-date CT has to date performed relatively poorly in discriminating between specific tissue types in carotid plaque [53, 91, 92], recent work [93-97] suggests that plaque with greater volumes of 'soft' or low-attenuation plaque relative to calcified plaque may represent a relatively simple scheme for identifying those carotid plaques most likely to cause ischemic symptoms. Prospective studies using these CT techniques to predict stroke risk are warranted now. Finally, the use of molecular and physiologic imaging with either radionuclides specific for plaque inflammation [98] or contrast-enhanced ultrasound [99] are emerging techniques that may also improve our ability to discriminate between high- and low-risk carotid plaques.

\section{Conclusion}

There is converging evidence to suggest that modern imaging techniques assessing cerebral hemodynamics and plaque vulnerability can improve risk stratification in asymptomatic carotid stenosis. The highest quality evidence thus far in the literature includes only systematic 
reviews and meta-analyses of cohort studies with no randomized trials having yet been performed to show how these newer imaging biomarkers could be used to inform treatment decisions in asymptomatic carotid stenosis. Beyond the need for randomized trials, there are additional important steps needed to improve the relevance of evidence supporting risk assessment strategies [6]. Imaging studies evaluating the risk of stroke in carotid disease should clearly define asymptomatic versus symptomatic disease, use uniform definitions of clearly defined outcome measures such as ipsilateral stroke, ensure that imaging interpretations are performed in a manner blinded to treatments and other risk factors, and include cohorts that are on modern intensive medical therapy. Such studies of risk stratification for asymptomatic carotid stenosis will be most valuable if they can integrate multiple high- risk features (including clinical risk factors) into a multifactorial risk assessment strategy in a manner that is relatively simple to implement and generalizable across a wide range of practice settings. Such high-quality evidence is needed to ensure that imaging techniques remain relevant with the evolving treatment and stroke risk trends that are major determinants of optimal stroke-prevention strategies.

\section{Grant Support}

Dr. Gupta's effort for this project has in part been supported by the Association of University Radiologists General Electric Radiology Research Academic Fellowship (GERRAF) and the 2014-2015 Foundation of the American Society of Neuroradiology Scholar Award.

\section{References}

1 Jonas DE, Feltner C, Amick HR, Sheridan S, Zheng ZJ, Watford DJ, Carter JL, Rowe CJ, Harris R: Screening for asymptomatic carotid artery stenosis: a systematic review and metaanalysis for the U.S. Preventive Services Task Force. Ann Intern Med 2014;161:336-346.

- North American Symptomatic Carotid Endarterectomy Trial Collaborators: Beneficial effect of carotid endarterectomy in symptomatic patients with high-grade carotid stenosis. N Engl J Med 1991;325:445-453.

-3 Randomised trial of endarterectomy for recently symptomatic carotid stenosis: final results of the MRC European Carotid Surgery Trial (ECST). Lancet 1998;351:1379-1387.

4 Endarterectomy for asymptomatic carotid artery stenosis. Executive Committee for the Asymptomatic Carotid Atherosclerosis Study. JAMA 1995;273:1421-1428.

5 Halliday A, Mansfield A, Marro J, Peto C, Peto R, Potter J, Thomas D; MRC Asymptomatic Carotid Surgery Trial (ACST) Collaborative Group: Prevention of disabling and fatal strokes by successful carotid endarterectomy in patients without recent neurological symptoms: randomised controlled trial. Lancet 2004;363:1491-1502.

6 Abbott AL, Nicolaides AN: Improving outcomes in patients with carotid stenosis: call for better research opportunities and standards. Stroke 2015;46:7-8.

7 Grotta JC: Clinical practice. Carotid stenosis. N Engl J Med 2013;369:1143-1150.

8 Naylor AR: Time to rethink management strategies in asymptomatic carotid artery disease. Nat Rev Cardiol 2011;9:116-124.

$\checkmark 9$ Spence JD: Asymptomatic carotid stenosis. Circulation 2013;127:739-742.

10 Abbott AL: Medical (nonsurgical) intervention alone is now best for prevention of stroke associated with asymptomatic severe carotid stenosis: results of a systematic review and analysis. Stroke 2009;40:e573-e583.

-11 Hadar N, Raman G, Moorthy D, O’Donnell TF, Thaler DE, Feldmann E, Lau J, Kitsios GD, Dahabreh IJ: Asymptomatic carotid artery stenosis treated with medical therapy alone: temporal trends and implications for risk assessment and the design of future studies. Cerebrovasc Dis 2014;38:163-173.

12 Raman G, Moorthy D, Hadar N, Dahabreh IJ, O'Donnell TF, Thaler DE, Feldmann E, Lau J, Kitsios GD: Management strategies for asymptomatic carotid stenosis: a systematic review and meta-analysis. Ann Intern Med 2013;158:676-685.

13 LeFevre ML; U.S. Preventive Services Task Force: Screening for asymptomatic carotid artery stenosis: U.S. Preventive Services Task Force recommendation statement. Ann Intern Med 2014;161:356-362.

14 Hosseini AA, Kandiyil N, Macsweeney ST, Altaf N, Auer DP: Carotid plaque hemorrhage on magnetic resonance imaging strongly predicts recurrent ischemia and stroke. Ann Neurol 2013;73:774-784.

15 Caplan LR, Hennerici M: Impaired clearance of emboli (washout) is an important link between hypoperfusion, embolism, and ischemic stroke. Arch Neurol 1998;55:1475-1482.

16 Gupta A, Chazen JL, Hartman M, Delgado D, Anumula N, Shao H, Mazumdar M, Segal AZ, Kamel H, Leifer D, Sanelli PC: Cerebrovascular reserve and stroke risk in patients with carotid stenosis or occlusion: a systematic review and meta-analysis. Stroke 2012;43:2884-2891.

17 Derdeyn CP: Mechanisms of ischemic stroke secondary to large artery atherosclerotic disease. Neuroimaging Clin N Am 2007; 17:303311 , vii-viii.
18 Phillips B, Ball C, Sackett D, Badenoch D, Straus S, Haynes B, Dawes M, Howick J: Oxford Centre for Evidence-Based Medicine - Levels of Evidence (March 2009). http://www.cebm. net/oxford-centre-evidence-based-medicinelevels-evidence-march-2009/ accessed Jan 10, 2015.

19 Derdeyn CP, Videen TO, Yundt KD, Fritsch SM, Carpenter DA, Grubb RL, Powers WJ: Variability of cerebral blood volume and oxygen extraction: stages of cerebral haemodynamic impairment revisited. Brain 2002;125:595-607.

20 Isozaki M, Arai Y, Kudo T, Kiyono Y, Kobayashi M, Kubota T, Kikuta K, Okazawa H: Clinical implication and prognosis of normal baseline cerebral blood flow with impaired vascular reserve in patients with major cerebral artery occlusive disease. Ann Nucl Med 2010;24:371-377.

21 Ogasawara K, Ogawa A, Terasaki K, Shimizu $\mathrm{H}$, Tominaga T, Yoshimoto T: Use of cerebrovascular reactivity in patients with symptomatic major cerebral artery occlusion to predict 5-year outcome: comparison of xenon-133 and iodine-123-IMP single-photon emission computed tomography. J Cereb Blood Flow Metab 2002;22:1142-1148.

22 Hasegawa Y, Yamaguchi T, Tsuchiya T, Minematsu K, Nishimura T: Sequential change of hemodynamic reserve in patients with major cerebral artery occlusion or severe stenosis. Neuroradiology 1992;34:15-21.

23 Eskey CJ, Sanelli PC: Perfusion imaging of cerebrovascular reserve. Neuroimaging Clin N Am 2005;15:367-381, xi.

-24 Bokkers RP, van Osch MJ, Klijn CJ, Kappelle LJ, Hendrikse J: Cerebrovascular reactivity within perfusion territories in patients with an internal carotid artery occlusion. J Neurol Neurosurg Psychiatry 2011;82:1011-1016. 
25 Bokkers RP, van Osch MJ, van der Worp HB, de Borst GJ, Mali WP, Hendrikse J: Symptomatic carotid artery stenosis: impairment of cerebral autoregulation measured at the brain tissue level with arterial spin-labeling MR imaging. Radiology 2010;256:201-208.

-26 Reinhard M, Schwarzer G, Briel M, Altamura C, Palazzo P, King A, Bornstein NM, Petersen N, Motschall E, Hetzel A, Marshall RS, Klijn CJ, Silvestrini M, Markus HS, Vernieri F: Cerebrovascular reactivity predicts stroke in high-grade carotid artery disease. Neurology 2014;83:1424-1431.

-27 Silvestrini M, Vernieri F, Pasqualetti P, Matteis M, Passarelli F, Troisi E, Caltagirone $\mathrm{C}$ : Impaired cerebral vasoreactivity and risk of stroke in patients with asymptomatic carotid artery stenosis. JAMA 2000;283:2122-2127.

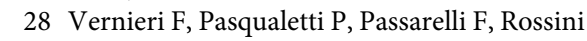
PM, Silvestrini M: Outcome of carotid artery occlusion is predicted by cerebrovascular reactivity. Stroke 1999;30:593-598.

-29 Tancredi FB, Hoge RD: Comparison of cerebral vascular reactivity measures obtained using breath-holding and $\mathrm{CO} 2$ inhalation. J Cereb Blood Flow Metab 2013;33:10661074.

-30 Vagal AS, Leach JL, Fernandez-Ulloa M, Zuccarello M: The acetazolamide challenge: techniques and applications in the evaluation of chronic cerebral ischemia. AJNR Am J Neuroradiol 2009;30:876-884.

- 31 Kuroda S, Kamiyama H, Abe H, Houkin K, Isobe $\mathrm{M}$, Mitsumori $\mathrm{K}$ : Acetazolamide test in detecting reduced cerebral perfusion reserve and predicting long-term prognosis in patients with internal carotid artery occlusion. Neurosurgery 1993;32:912-918; discussion 918-919.

-32 Grubb RL Jr, Derdeyn CP, Fritsch SM, Carpenter DA, Yundt KD, Videen TO, Spitznagel EL, Powers WJ: Importance of hemodynamic factors in the prognosis of symptomatic carotid occlusion. JAMA 1998;280:1055-1060.

33 Powers WJ: Cerebral hemodynamics in ischemic cerebrovascular disease. Ann Neurol 1991;29:231-240.

-34 Yamauchi H, Fukuyama H, Nagahama Y, Nabatame H, Nakamura K, Yamamoto Y, Yonekura Y, Konishi J, Kimura J: Evidence of misery perfusion and risk for recurrent stroke in major cerebral arterial occlusive diseases from PET. J Neurol Neurosurg Psychiatry 1996;61:18-25.

-35 Yamauchi H, Higashi T, Kagawa S, Nishii R, Kudo T, Sugimoto K, Okazawa H, Fukuyama $\mathrm{H}$ : Is misery perfusion still a predictor of stroke in symptomatic major cerebral artery disease? Brain 2012;135:2515-2526.

- 36 Gupta A, Baradaran H, Schweitzer AD, Kamel H, Pandya A, Delgado D, Wright D, Hurtado-Rua S, Wang Y, Sanelli PC: Oxygen extraction fraction and stroke risk in patients with carotid stenosis or occlusion: a systematic review and meta-analysis. AJNR Am J Neuroradiol 2014;35:250-255.
7 Stary HC, Chandler AB, Dinsmore RE, Fuster $\mathrm{V}$, Glagov S, Insull W Jr, Rosenfeld ME, Schwartz CJ, Wagner WD, Wissler RW: A definition of advanced types of atherosclerotic lesions and a histological classification of atherosclerosis. A report from the committee on vascular lesions of the council on arteriosclerosis, American heart association. Circulation 1995;92:1355-1374.

38 Cai JM, Hatsukami TS, Ferguson MS, Small R, Polissar NL, Yuan C: Classification of human carotid atherosclerotic lesions with in vivo multicontrast magnetic resonance imaging. Circulation 2002;106:1368-1373.

39 Yuan C, Zhang SX, Polissar NL, Echelard D, Ortiz G, Davis JW, Ellington E, Ferguson MS, Hatsukami TS: Identification of fibrous cap rupture with magnetic resonance imaging is highly associated with recent transient ischemic attack or stroke. Circulation 2002;105: 181-185.

40 Saam T, Ferguson MS, Yarnykh VL, Takaya $\mathrm{N}, \mathrm{Xu}$ D, Polissar NL, Hatsukami TS, Yuan C: Quantitative evaluation of carotid plaque composition by in vivo MRI. Arterioscler Thromb Vasc Biol 2005;25:234-239.

-41 Takaya N, Yuan C, Chu B, Saam T, Underbill H, Cai J, Tran N, Polissar NL, Isaac C, Ferguson MS, Garden GA, Cramer SC, Maravilla KR, Hashimoto B, Hatsukami TS: Association between carotid plaque characteristics and subsequent ischemic cerebrovascular events: a prospective assessment with MRI - initial results. Stroke 2006;37:818-823.

42 Altaf N, MacSweeney ST, Gladman J, Auer DP: Carotid intraplaque hemorrhage predicts recurrent symptoms in patients with highgrade carotid stenosis. Stroke 2007;38:16331635.

43 Singh N, Moody AR, Gladstone DJ, Leung G, Ravikumar R, Zhan J, Maggisano R: Moderate carotid artery stenosis: MR imaging-depicted intraplaque hemorrhage predicts risk of cerebrovascular ischemic events in asymptomatic men. Radiology 2009;252:502508.

44 Sadat U, Teng Z, Young VE, Walsh SR, Li ZY, Graves MJ, Varty K, Gillard JH: Association between biomechanical structural stresses of atherosclerotic carotid plaques and subsequent ischaemic cerebrovascular events - a longitudinal in vivo magnetic resonance imaging-based finite element study. Eur J Vasc Endovasc Surg 2010;40:485-491.

-45 Kwee RM, van Oostenbrugge RJ, Mess WH, Prins MH, van der Geest RJ, Ter Berg JW, Franke CL, Korten AG, Meems BJ, van Engelshoven JM, Wildberger JE, Kooi ME: MRI of carotid atherosclerosis to identify TIA and stroke patients who are at risk of a recurrence. J Magn Reson Imaging 2013;37:11891194.

46 Gupta A, Baradaran H, Schweitzer AD, Kamel H, Pandya A, Delgado D, Dunning A, Mushlin AI, Sanelli PC: Carotid plaque MRI and stroke risk: a systematic review and metaanalysis. Stroke 2013;44:3071-3077.
47 Altaf N, Akwei S, Auer DP, Macsweeney ST, Lowe J: Magnetic resonance detected carotid plaque hemorrhage is associated with inflammatory features in symptomatic carotid plaques. Ann Vasc Surg 2013;27:655-661.

48 Altaf N, Daniels L, Morgan PS, Auer D, MacSweeney ST, Moody AR, Gladman JR: Detection of intraplaque hemorrhage by magnetic resonance imaging in symptomatic patients with mild to moderate carotid stenosis predicts recurrent neurological events. J Vasc Surg 2008;47:337-342.

49 Gupta A, Baradaran H, Kamel H, Mangla A, Pandya A, Fodera V, Dunning A, Sanelli PC: Intraplaque high-intensity signal on $3 \mathrm{D}$ timeof-flight MR angiography is strongly associated with symptomatic carotid artery stenosis. AJNR Am J Neuroradiol 2014;35:557561.

50 Kandiyil N, Altaf N, Hosseini AA, MacSweeney ST, Auer DP: Lower prevalence of carotid plaque hemorrhage in women, and its mediator effect on sex differences in recurrent cerebrovascular events. PLoS One 2012; 7:e47319.

51 Qiao Y, Etesami M, Astor BC, Zeiler SR, Trout HH 3rd, Wasserman BA: Carotid plaque neovascularization and hemorrhage detected by MR imaging are associated with recent cerebrovascular ischemic events. AJNR Am J Neuroradiol 2012;33:755-760.

52 Qiao Y, Etesami M, Malhotra S, Astor BC, Virmani R, Kolodgie FD, Trout HH 3rd, Wasserman BA: Identification of intraplaque hemorrhage on MR angiography images: a comparison of contrast-enhanced mask and time-of-flight techniques. AJNR Am J Neuroradiol 2011;32:454-459.

53 U-King-Im JM, Fox AJ, Aviv RI, Howard P, Yeung R, Moody AR, Symons SP: Characterization of carotid plaque hemorrhage: a CT angiography and MR intraplaque hemorrhage study. Stroke 2010;41:1623-1629.

54 Yamada K, Song Y, Hippe DS, Sun J, Dong L, Xu D, Ferguson MS, Chu B, Hatsukami TS, Chen M, Zhou C, Yuan C: Quantitative evaluation of high intensity signal on MIP images of carotid atherosclerotic plaques from routine TOF-MRA reveals elevated volumes of intraplaque hemorrhage and lipid rich necrotic core. J Cardiovasc Magn Reson 2012; 14:81.

55 Yamada N, Higashi M, Otsubo R, Sakuma T, Oyama N, Tanaka R, Iihara K, Naritomi $H$, Minematsu K, Naito H: Association between signal hyperintensity on T1-weighted MR imaging of carotid plaques and ipsilateral ischemic events. AJNR Am J Neuroradiol 2007; 28:287-292.

56 Saam T, Hetterich H, Hoffmann V, Yuan C, Dichgans M, Poppert H, Koeppel T, Hoffmann U, Reiser MF, Bamberg F: Meta-analysis and systematic review of the predictive value of carotid plaque hemorrhage on cerebrovascular events by magnetic resonance imaging. J Am Coll Cardiol 2013;62:10811091. 
57 Kuk M, Wannarong T, Beletsky V, Parraga G, Fenster A, Spence JD: Volume of carotid artery ulceration as a predictor of cardiovascular events. Stroke 2014;45:1437-1441.

58 Hirt LS: Progression rate and ipsilateral neurological events in asymptomatic carotid stenosis. Stroke 2014;45:702-706.

-59 Grønholdt ML, Nordestgaard BG, Schroeder TV, Vorstrup S, Sillesen H: Ultrasonic echolucent carotid plaques predict future strokes. Circulation 2001;104:68-73.

60 Kakkos SK, Griffin MB, Nicolaides AN, Kyriacou E, Sabetai MM, Tegos T, Makris GC, Thomas DJ, Geroulakos G; Asymptomatic Carotid Stenosis and Risk of Stroke (ACSRS) Study Group: The size of juxtaluminal hypoechoic area in ultrasound images of asymptomatic carotid plaques predicts the occurrence of stroke. J Vasc Surg 2013;57:609-618. e1; discussion 617-618.

61 Langsfeld M, Gray-Weale AC, Lusby RJ: The role of plaque morphology and diameter reduction in the development of new symptoms in asymptomatic carotid arteries. J Vasc Surg 1989;9:548-557.

62 Mathiesen EB, Bønaa KH, Joakimsen O: Echolucent plaques are associated with high risk of ischemic cerebrovascular events in carotid stenosis: the tromsø study. Circulation 2001;103:2171-2175.

-63 Nicolaides AN, Kakkos SK, Griffin M, Sabetai M, Dhanjil S, Thomas DJ, Geroulakos G, Georgiou N, Francis S, Ioannidou E, Dore CJ; Asymptomatic Carotid Stenosis and Risk of Stroke (ACSRS) Study Group: Effect of image normalization on carotid plaque classification and the risk of ipsilateral hemispheric ischemic events: results from the asymptomatic carotid stenosis and risk of stroke study. Vascular 2005;13:211-221.

-64 O’Holleran LW, Kennelly MM, McClurken M, Johnson JM: Natural history of asymptomatic carotid plaque. Five year follow-up study. Am J Surg 1987;154:659-662.

65 Polak JF, Shemanski L, O'Leary DH, Lefkowitz D, Price TR, Savage PJ, Brant WE, Reid C: Hypoechoic plaque at US of the carotid artery: an independent risk factor for incident stroke in adults aged 65 years or older. Cardiovascular Health Study. Radiology 1998;208:649654.

-66 Silvestrini M, Altamura C, Cerqua R, Pasqualetti P, Viticchi G, Provinciali L, Paulon L, Vernieri F: Ultrasonographic markers of vascular risk in patients with asymptomatic carotid stenosis. J Cereb Blood Flow Metab 2013;33:619-624.

-67 Topakian R, King A, Kwon SU, Schaafsma A, Shipley M, Markus HS; ACES Investigators: Ultrasonic plaque echolucency and emboli signals predict stroke in asymptomatic carotid stenosis. Neurology 2011;77:751-758.

-68 Gupta A, Kesavabhotla K, Baradaran H, Kamel H, Pandya A, Giambrone AE, Wright D, Pain KJ, Mtui EE, Suri JS, Sanelli PC, Mushlin AI: Plaque echolucency and stroke risk in asymptomatic carotid stenosis: a systematic re- view and meta-analysis. Stroke 2015;46:9197.

69 El-Barghouty NM, Levine T, Ladva S, Flanagan A, Nicolaides A: Histological verification of computerised carotid plaque characterisation. Eur J Vasc Endovasc Surg 1996;11:414416.

70 Grønholdt ML, Nordestgaard BG, Wiebe BM, Wilhjelm JE, Sillesen H: Echo-lucency of computerized ultrasound images of carotid atherosclerotic plaques are associated with increased levels of triglyceride-rich lipoproteins as well as increased plaque lipid content. Circulation 1998;97:34-40.

71 Spence JD, Tamayo A, Lownie SP, Ng WP, Ferguson GG: Absence of microemboli on transcranial Doppler identifies low-risk patients with asymptomatic carotid stenosis. Stroke 2005;36:2373-2378

72 Abbott AL, Chambers BR, Stork JL, Levi CR, Bladin CF, Donnan GA: Embolic signals and prediction of ipsilateral stroke or transient ischemic attack in asymptomatic carotid stenosis: a multicenter prospective cohort study. Stroke 2005;36:1128-1133.

73 Molloy J, Markus HS: Asymptomatic embolization predicts stroke and TIA risk in patients with carotid artery stenosis. Stroke 1999;30: 1440-1443.

74 Markus HS, King A, Shipley M, Topakian R, Cullinane M, Reihill S, Bornstein NM, Schaafsma A: Asymptomatic embolisation for prediction of stroke in the Asymptomatic Carotid Emboli Study (ACES): a prospective observational study. Lancet Neurol 2010;9: 663-671.

75 Russell D, Madden KP, Clark WM, Sandset PM, Zivin JA: Detection of arterial emboli using Doppler ultrasound in rabbits. Stroke 1991;22:253-258.

76 Markus HS, Brown MM: Differentiation between different pathological cerebral embolic materials using transcranial Doppler in an in vitro model. Stroke 1993;24:1-5.

77 Bokkers RP, van Osch MJ, Klijn CJ, Kappelle LJ, Hendrikse J: Cerebrovascular reactivity within perfusion territories in patients with an internal carotid artery occlusion. J Neurol Neurosurg Psychiatry 2011;82:1011-1016.

78 Gauthier CJ, Desjardins-Crepeau L, Madjar C, Bherer L, Hoge RD: Absolute quantification of resting oxygen metabolism and metabolic reactivity during functional activation using QUO2 MRI. Neuroimage 2012;63: 1353-1363.

79 Hare HV, Germuska M, Kelly ME, Bulte DP: Comparison of $\mathrm{CO} 2$ in air versus carbogen for the measurement of cerebrovascular reactivity with magnetic resonance imaging. J Cereb Blood Flow Metab 2013;33:1799-1805.

80 Heijtel DF, Mutsaerts HJ, Bakker E, Schober P, Stevens MF, Petersen ET, van Berckel BN, Majoie CB, Booij J, van Osch MJ, Vanbavel E, Boellaard R, Lammertsma AA, Nederveen AJ: Accuracy and precision of pseudo-continuous arterial spin labeling perfusion during baseline and hypercapnia: a head-to-head comparison with (1)(5) $\mathrm{O} \mathrm{H}_{2} \mathrm{O}$ positron emission tomography. Neuroimage 2014;92:182192.

81 Leoni RF, Mazzetto-Betti KC, Silva AC, Dos Santos AC, de Araujo DB, Leite JP, PontesNeto OM: Assessing cerebrovascular reactivity in carotid steno-occlusive disease using MRI bold and ASL techniques. Radiol Res Pract 2012;2012:268483.

82 Tancredi FB, Gauthier CJ, Madjar C, Bolar DS, Fisher JA, Wang DJ, Hoge RD: Comparison of pulsed and pseudocontinuous arterial spin-labeling for measuring $\mathrm{CO} 2$-induced cerebrovascular reactivity. J Magn Reson Imaging 2012;36:312-321.

-83 Winter JD, Fierstra J, Dorner S, Fisher JA, St Lawrence KS, Kassner A: Feasibility and precision of cerebral blood flow and cerebrovascular reactivity MRI measurements using a computer-controlled gas delivery system in an anesthetised juvenile animal model. J Magn Reson Imaging 2010;32:1068-1075.

84 Zhang J, Liu T, Gupta A, Spincemaille P, Nguyen TD, Wang Y: Quantitative mapping of cerebral metabolic rate of oxygen (CMRO2) using quantitative susceptibility mapping (QSM). Magn Reson Med 2014, Epub ahead of print.

85 Fan AP, Evans KC, Stout JN, Rosen BR, Adalsteinsson E: Regional quantification of cerebral venous oxygenation from MRI susceptibility during hypercapnia. Neuroimage 2015; 104:146-155.

86 Gauthier CJ, Hoge RD: Magnetic resonance imaging of resting $\mathrm{OEF}$ and $\mathrm{CMRO} 2$ using a generalized calibration model for hypercapnia and hyperoxia. Neuroimage 2012;60: 1212-1225.

87 Sabeti S, Schlager O, Exner M, Mlekusch W, Amighi J, Dick P, Maurer G, Huber K, Koppensteiner R, Wagner O, Minar E, Schillinger M: Progression of carotid stenosis detected by duplex ultrasonography predicts adverse outcomes in cardiovascular high-risk patients. Stroke 2007;38:2887-2894.

88 Bertges DJ, Muluk V, Whittle J, Kelley M, MacPherson DS, Muluk SC: Relevance of carotid stenosis progression as a predictor of ischemic neurological outcomes. Arch Intern Med 2003;163:2285-2289.

89 Ballotta E, Da Giau G, Meneghetti G, Barbon B, Militello C, Baracchini C: Progression of atherosclerosis in asymptomatic carotid arteries after contralateral endarterectomy: a 10 -year prospective study. J Vasc Surg 2007; 45:516-522.

90 Balestrini S, Lupidi F, Balucani C, Altamura C, Vernieri F, Provinciali L, Silvestrini M: One-year progression of moderate asymptomatic carotid stenosis predicts the risk of vascular events. Stroke 2013;44:792-794.

-91 Walker LJ, Ismail A, McMeekin W, Lambert D, Mendelow AD, Birchall D: Computed tomography angiography for the evaluation of carotid atherosclerotic plaque: correlation with histopathology of endarterectomy specimens. Stroke 2002;33:977-981. 
$>92$ Wintermark M, Jawadi SS, Rapp JH, Tihan T, Tong E, Glidden DV, Abedin S, Schaeffer S, Acevedo-Bolton G, Boudignon B, Orwoll B, Pan X, Saloner D: High-resolution CT imaging of carotid artery atherosclerotic plaques. AJNR Am J Neuroradiol 2008;29: 875-882.

93 Grimm JM, Schindler A, Schwarz F, Cyran CC, Bayer-Karpinska A, Freilinger T, Yuan C, Linn J, Trelles M, Reiser MF, Nikolaou K, Saam T: Computed tomography angiography vs $3 \mathrm{~T}$ black-blood cardiovascular magnetic resonance for identification of symptomatic carotid plaques. J Cardiovasc Magn Reson 2014;16:84.
94 Hetterich H, Willner M, Fill S, Herzen J, Bamberg F, Hipp A, Schuller U, Adam-Neumair S, Wirth S, Reiser M, Pfeiffer F, Saam T: Phasecontrast CT: qualitative and quantitative evaluation of atherosclerotic carotid artery plaque. Radiology 2014;271:870-878.

95 Gupta A, Baradaran H, Kamel H, Pandya A, Mangla A, Dunning A, Marshall RS, Sanelli PC: Evaluation of computed tomography angiography plaque thickness measurements in high-grade carotid artery stenosis. Stroke 2014;45:740-745.

96 Gupta A, Mtui EE, Baradaran H, Salama G, Pandya A, Kamel H, Giambrone A, Sanelli PC: CT angiographic features of symptomproducing plaque in moderate-grade carotid artery stenosis. AJNR Am J Neuroradiol 2015; 36:349-354.
97 Trelles M, Eberhardt KM, Buchholz M, Schindler A, Bayer-Karpinska A, Dichgans M, Reiser MF, Nikolaou K, Saam T: CTA for screening of complicated atherosclerotic carotid plaque - American heart association type VI lesions as defined by MRI. AJNR Am J Neuroradiol 2013;34:2331-2337.

98 Saito H, Kuroda S, Hirata K, Magota K, Shiga T, Tamaki N, Yoshida D, Terae S, Nakayama N, Houkin K: Validity of dual MRI and FFDG PET imaging in predicting vulnerable and inflamed carotid plaque. Cerebrovasc Dis 2013;35:370-377.

99 Alonso A, Artemis D, Hennerici MG: Molecular imaging of carotid plaque vulnerability. Cerebrovasc Dis 2015;39:5-12. 